\title{
Sensitivity of pregnancy field on the COVID-19 case report form among pregnancies completed through December 31, 2020 - Illinois and Tennessee
}

\author{
Susan E. Manning ( $\nabla$ aci6@cdc.gov) \\ CDC \\ Amanda Bennett \\ CDC, Illinois Dept. of Public Health \\ Sascha Ellington \\ CDC \\ Sonal Goyal \\ CDC, Illinois Dept. of Public Health \\ Elizabeth Harvey \\ CDC, Tennessee Dept. of Public Health \\ Lindsey Sizemore \\ CDC, Tennessee Dept. of Public Health \\ Heather Wingate \\ CDC, Tennessee Dept. of Public Health
}

\section{Short Report}

Keywords: SARS-CoV-2 infection, COVID-19, pregnancy, validation, surveillance

Posted Date: June 30th, 2021

DOI: https://doi.org/10.21203/rs.3.rs-669059/v1

License: (c) (1) This work is licensed under a Creative Commons Attribution 4.0 International License. Read Full License

Version of Record: A version of this preprint was published at Maternal and Child Health Journal on November 10th, 2021. See the published version at https://doi.org/10.1007/s10995-021-03263-8. 


\section{Abstract}

Introduction: The considerable volume of infections from SARS-CoV-2, the virus that causes coronavirus disease 2019 (COVID-19), has made it challenging for health departments to collect complete data for national disease reporting. We sought to examine sensitivity of the COVID-19 case report form (CRF) pregnancy field by comparing CRF data to the gold standard of CRF data linked to birth and fetal death certificates.

Methods: CRFs for women aged 15-44 years with laboratory-confirmed SARS-CoV-2 infection were linked to birth and fetal death certificates for pregnancies completed during January 1-December 31, 2020 in Illinois and Tennessee. Among linked records, pregnancy was considered confirmed for women with a SARS-CoV-2 specimen collection date on or prior to the delivery date. Sensitivity of the COVID-19 CRF pregnancy field was calculated by dividing the number of confirmed pregnant women with SARS-CoV-2 infection with pregnancy indicated on the CRF by the number of confirmed pregnant women with SARS-CoV-2 infection.

Results: Among 4,276 (Illinois) and 2,070 (Tennessee) CRFs that linked with a birth or fetal death certificate, CRF pregnancy field sensitivity was $45.3 \%$ and $42.1 \%$, respectively. In both states, sensitivity varied significantly by maternal race/ethnicity, insurance, trimester of prenatal care entry, month of specimen collection, and trimester of specimen collection. Sensitivity also varied by maternal education in Illinois but not in Tennessee.

Discussion: Sensitivity of the COVID-19 CRF pregnancy field varied by state and demographic factors. To more accurately assess outcomes for pregnant women, jurisdictions might consider utilizing additional data sources and linkages to obtain pregnancy status.

\section{Introduction}

State, local, and territorial public health departments voluntarily report infections from SARS-CoV-2, the virus that causes coronavirus disease 2019 (COVID-19), to the Centers for Disease Control and Prevention (CDC) as part of surveillance of nationally notifiable conditions. The COVID-19 case report form (CRF) was developed by CDC to standardize the reporting of information on cases, including demographics, exposures, contact history, and clinical course and management (Centers for Disease Control and Prevention, 2020c). The current version of the COVID-19 CRF is two pages in length and contains over 100 data elements. The considerable volume of COVID-19 cases occurring during the pandemic has made it challenging for state and local health departments to conduct thorough case investigations and collect all requested data elements. Jurisdictions must often prioritize collecting those data elements needed to trace close contacts and prevent transmission of infection (CDC, 2020a \& 2020d). As a result, the national COVID-19 surveillance database is incomplete for many requested data elements, including pregnancy status (Stokes et al, 2020).

Previous studies have shown that pregnant people are at increased risk of severe illness from COVID-19 when compared to nonpregnant people (Zambrano et. al, 2020; Ellington et. al, 2020; Delahoy et al, 2020; Panagiotakopoulos et al, 2020; Allotey et al, 2020). Two CDC analyses using national COVID-19 surveillance data found that pregnant women with SARS-CoV-2 infection were more likely to have adverse outcomes (e.g., intensive care unit [ICU] admissions, mechanical ventilation, extracorporeal membrane oxygenation, and death) than nonpregnant women (Zambrano et. al, 2020; Ellington et al, 2020). However, a limitation of those analyses was that pregnancy status was missing for more than two-thirds of women of reproductive age (WRA), defined as women aged 15-44 years. We sought to examine the sensitivity of the COVID-19 CRF pregnancy field and to identify systematic differences in the percentage of confirmed pregnant women with SARS-CoV-2 infection with pregnancy indicated on the CRF.

\section{Methods}

In both Illinois and Tennessee, local or regional health departments are responsible for case investigations and monitoring of reports of COVID-19, including collecting information needed to complete the CRF. The majority of COVID-19 reports are received through laboratory reporting of SARS-CoV-2 infections, which typically do not include information on whether the infected person was pregnant at the time of testing. CRF data collected by local health departments are entered into the National Electronic Disease Surveillance System (NEDSS) Base System (NBS), which houses all reportable conditions except HIV and sexually transmitted infections. CRFs for persons with laboratory-confirmed SARS-CoV-2 infection were linked to birth and fetal death certificates with pregnancy completion dates during January 1, 2020-December 31, 2020 in Illinois and Tennessee. Linkage methodology differed by state. Illinois used Linkplus software to conduct probabilistic linkages to match CRFs for females aged 10-55 years with birth and fetal death certificates, relying on phonetic first name, current last name, maiden last name, date of birth, and address as linkage variables. Tennessee used deterministic linkages in SAS version 9.4 to match CRFs for non-males born on or after January 1, 1960 to birth and fetal death certificates using phonetic first name, current last name, maiden last name, date of birth, and social security number (if available). For the remainder of this paper, CRFs that 
linked to a birth or fetal death certificate and had a positive SARS-CoV-2 specimen collected during pregnancy or on the delivery date will be referred to as "confirmed pregnant women with SARS-CoV-2 infection." CRFs that linked with a vital record but had specimen collection date after the delivery date were excluded from further analysis.

Among confirmed pregnant women with SARS-CoV-2 infection, both states limited the analytic sample for this study to those aged 15-44 years. The sensitivity of the CRF pregnancy field was calculated as the percentage of confirmed pregnant women with SARS-CoV-2 infection for which pregnancy was indicated on the CRF; CRFs with pregnancy status 'No,' 'Unknown' or missing were considered as not indicating pregnancy. Chi-square tests were used to test for significant differences in sensitivity by: race/ethnicity, age, education, insurance (delivery payer), and 1st trimester initiation of prenatal care (derived from birth and fetal death certificates), and month and pregnancy trimester of SARS-CoV-2 specimen collection (derived from CRFs). This activity was reviewed by CDC and was conducted consistent with applicable federal law and CDC policy.

\section{Results}

The percentage of WRA with laboratory-confirmed SARS-CoV-2 infection that were confirmed to be pregnant at the time of infection was $1.8 \%(4,276 / 235,209)$ in Illinois and $1.5 \%(2,070 / 135,659)$ in Tennessee. Among all CRFs that indicated the infected woman was pregnant, $50.3 \%(1,936 / 3,849)$ in Illinois and $43.6 \%(872 / 1,999)$ in Tennessee linked with a birth or fetal death certificate with delivery on or before December 31,2020 . The sensitivity of the CRF pregnancy field was $45.3 \%$ in Illinois $(1,936 / 4,276)$ and $42.1 \%$ in Tennessee $(872 / 2,070)$ (Table 1).

Sensitivity of the pregnancy field varied by demographic characteristics. Sensitivity varied by maternal race/ethnicity in both states ( $p<$ 0.05), with lower sensitivity observed among White, non-Hispanic women in Illinois and among Black, non-Hispanic women in Tennessee. Sensitivity did not vary by maternal age in either state. Sensitivity varied by maternal education in Illinois, with lower sensitivity observed among women with a Bachelor's degree or higher, but did not vary significantly in Tennessee. Sensitivity varied significantly by maternal insurance status in both states, with lower sensitivity observed among women with no insurance or self-pay. In both states, sensitivity was higher among women who initiated prenatal care in the first trimester compared with those who had no prenatal care or initiated care in the second trimester or later. In both states, sensitivity differed significantly by month of specimen collection; however, the patterns differed by state. In Tennessee sensitivity tended to decrease with each month as the pandemic progressed, whereas Illinois observed more variability in sensitivity by month. Sensitivity also varied by trimester of positive specimen collection in both states, with higher sensitivity in the first and second semesters of pregnancy compared with the third trimester.

\section{Discussion}

These findings highlight the importance of improving the completeness and accuracy of the COVID-19 CRF pregnancy field. Using birth and fetal death certificates as the gold standard for ascertaining pregnancy status, under-ascertainment of pregnant women with SARSCoV-2 infection was observed in both Illinois and Tennessee. This level of incompleteness and inaccuracy has implications for the interpretation and generalizability of studies relying solely on CRF data, and reporting jurisdictions should identify strategies to improve ascertainment of pregnancy status.

Timely pregnancy information is particularly important for efforts to gather real-time information on the impact of emerging infections occurring throughout pregnancy. Linkages to additional data sources that can serve as an alternative method to identify pregnancy status, such as vital records as conducted in this study, might not be possible until after the pregnancy is completed, which can be several months after the infection occurred. Although valuable, more timely information on infections during pregnancy allows for the provision of information about the impact of COVID-19 in pregnancy, the importance of seeking appropriate medical care, the risk for severe illness or adverse pregnancy outcomes, and recommendations for preventing the spread of infection to close contacts including the neonate.

The sensitivity of the CRF pregnancy field varied by state and certain demographic factors. In Tennessee, sensitivity was higher among non-Hispanic White women compared with women of color and in Illinois sensitivity was higher among non-Hispanic Black women. In both states, sensitivity varied significantly by maternal race/ethnicity, insurance, trimester of prenatal care entry, month of specimen collection, and trimester of specimen collection. Sensitivity also varied by maternal education in Illinois but not in Tennessee. These results might reflect differences among populations in their response to case investigator attempts to contact them; willingness to disclose information, including pregnancy status, once contact has been made (assuming information on pregnancy status is systematically collected from all women reported to have SARS-CoV-2 infection); fear of discrimination; or distrust of government entities (Petkovic et al, 2019; Davis et at 2010; Kirst et al, 2013). These findings have implications for the interpretation of surveillance data on 
COVID-19 in pregnancy by race/ethnicity. National data indicate that persons of color are infected with SARS-CoV-2 at higher rates than white people (The COVID Tracking Project, 2020). If the sensitivity of the CRF pregnancy field is lower for women of color, as was observed in Tennessee, use of CRF data would underestimate inequities in SARS-CoV-2 infection in pregnancy by race/ethnicity. However, if the sensitivity of the pregnancy field is lower for White women, as was observed in Illinois, use of CRF data would overestimate inequities in SARS-CoV-2 infection in pregnancy. Furthermore, studies that rely on the CRF alone to examine outcomes for women with COVID-19 during pregnancy might fail to accurately estimate potential differences in severity of infection and adverse outcomes among racial and ethnic groups.

Both states found substantial numbers of CRFs that indicated a woman was pregnant but did not link with a birth or fetal death certificate. There are several reasons why a linkage might not have occurred. Many of these unlinked CRFs are likely to represent women who are still pregnant and therefore had not had a completed delivery resulting in a birth or fetal death certificate that was available at the time of data linkage. Both states include a data field on the CRF for estimated date of delivery for women indicated to be pregnant. While this field is not always completed, when it is complete, the information can be used to determine whether it is likely the individual is still pregnant as of the time of data linkage. Tennessee also collects the name of the obstetric provider when pregnancy is indicated on the CRF, which enables follow-up with the obstetrician for unlinked records to request information on the pregnancy outcome.

Some unlinked records might represent deliveries that occurred outside the maternal state of residence. While birth and fetal death certificates for out-of-state occurrences are reported to the jurisdiction where the woman resides, there is a substantial time lag associated with this process and the vital records might not have been available at the time the linkages were conducted. There is also a time lag for capturing vital events in provisional birth and fetal deaths files, and therefore some deliveries that have occurred might not have linked for the current analysis but will link in future matches. Both states will continue to perform cumulative linkages between CRF and birth/fetal death certificate data for pregnant women that do not link until it is reasonable to assume the pregnancy should have been completed and the result of the pregnancy remains unknown.

The unlinked CRFs might also represent situations in which the CRF will not link with vital records, including early pregnancy losses, pregnancy terminations, unreported fetal deaths or stillbirths, maternal deaths that occurred prior to delivery, or relocation of the woman to another jurisdiction. In both states fetal deaths are required to be reported when the fetus is at least 20 weeks gestation and/or 350 grams; therefore, fetal deaths occurring before 20 weeks gestation might not have a corresponding fetal death certificate and will remain unlinked. Data quality issues including misspellings, data entry errors, and incorrectly entered pregnancy status can also result in unlinked records.

In summary, these findings from two states indicate that the sensitivity of the COVID-19 CRF pregnancy field varied by state and certain demographic factors. Analyses that rely on CRF data alone should be interpreted in the context of these limitations. Further investigation is needed to better understand and mitigate the factors that contribute to incomplete or inaccurate pregnancy information on the CRF. In addition to the factors discussed above that affect the likelihood of case investigators successfully contacting an infected person and that person's willingness to disclose information, inadequate training for case investigators/contact tracers on the importance of collecting information on pregnancy can be an important contributor to incomplete data. In the absence of complete pregnancy status data on the COVID-19 CRF, reporting jurisdictions might consider linkage to birth and fetal death certificates to ascertain this information. Data linkage can reduce the amount of incomplete and inaccurate data when time and resources are insufficient to complete thorough case investigations for all reported cases. In addition to improving information on pregnancy status, linkages to vital records can be used to improve the quality of other data elements including race/ethnicity and other demographic characteristics. However, relying on data linkages alone to identify infections during pregnancy does introduce some bias because cases that will not have a birth of death certificate (such as early losses and terminations) will be systematically missed in the linkage. Therefore, use of data linkages in combination with pregnancy information available on the CRF will provide a more comprehensive picture of the burden of SARS-CoV-2 infection in pregnancy. Jurisdictions that are using data linkages to improve their identification of pregnant women for COVID-19 surveillance can consider establishing processes to provide information back to infectious disease surveillance systems to improve the completeness and quality of the CRF data. Because states vary in their processes for completing the COVID-19 CRF, timing of access to provisional birth and fetal death records, and experience with and capacity to conduct data linkages, it is uncertain how well these findings from two states can be generalized to other reporting jurisdictions.

These results also speak to the importance of implementing enhanced pregnancy surveillance efforts to provide more detailed information on the impact of SARS-CoV-2 infection on pregnant women and their infants. CDC, in collaboration with state and local health departments, has initiated COVID-19 pregnancy surveillance to report pregnancy-related information and outcomes among pregnant women with laboratory-confirmed SARS-CoV-2 infection (CDC, 2020b; Woodworth et al, 2020). Improving the quality of CRF pregnancy 
data or using data linkages to improve identification of pregnant women provides a more complete enumeration of women with SARSCoV-2 infection during pregnancy that can serve as the sampling frame for medical record abstraction to gather more detailed information on maternal and infant outcomes. These data can provide timely and important information to inform clinical guidance and prevention strategies.

\section{Declarations}

Disclaimer: The findings and conclusions in this paper are those of the authors and do not necessarily represent the official position of the Centers for Disease Control and Prevention.

The authors have no conflicts of interest to disclose.

\section{Acknowledgements}

The authors would like to acknowledge the Illinois Department of Public Health, Division of Infectious Disease, and the Illinois Department of Vital Records for the provision of the data used in this analysis; Jessica Schultz, MPH, Jason Cummins, MPH, Vanessa Lefler, PhD, Morgan McDonald, MD, FAAP, Pamela and Talley, MD, MPH from the Tennessee Department of Health; and the CDC Pregnancy and Infant Linked Outcomes Team.

\section{References}

1. Allotey, J., Stallings, E., Bonet, M., Yap, M., Chatterjee, S., Kew, T., et al. (2020). Clinical manifestations, risk factors, and maternal and perinatal outcomes of coronavirus disease 2019 in pregnancy: living systematic review and meta-analysis. BMJ; 370(m3320) http://dx.doi.org/10.1136/bmj.m3320.

2. Centers for Disease Control and Prevention (2020a). CDC COVID Data Tracker. Retrieved September 7, 2020 from https://www.cdc.gov/coronavirus/2019-ncov/cases-updates/cases-in-us.html. Accessed on 9/7/2020.

3. Centers for Disease Control and Prevention (2020b). Data on COVID-19 During Pregnancy. Retrieved September 17, 2020 from https://www.cdc.gov/coronavirus/2019-ncov/cases-updates/special-populations/pregnancy-data-on-covid-19.html.

4. Centers for Disease Control and Prevention (2020c). Human Infection with 2019 Novel Coronavirus Case Report Form. Retrieved September 14, 2020 from https://www.cdc.gov/coronavirus/2019-ncov/downloads/pui-form.pdf..

5. Centers for Disease Control and Prevention (2020d). Instructions for Completing the Human Infection with 2019 Novel Coronavirus (COVID-19) Case Report Form. Retrieved September 14, 2020 from https://www.cdc.gov/coronavirus/2019-ncov/downloads/COVID19-Persons-Under-Investigation-and-Case-Report-Form-Instructions.pdf.

6. The COVID Tracking Project (2020). The COVID Racial Data Tracker. Retrieved October 11, 2020 https://covidtracking.com/race.

7. Davis, R.E., Couper, M.P., Janz, N.K., Caldwell, C.H., \& Resnicow K. (2010). Interviewer effects in public health surveys. Health Educ Res;25(1):14-26. doi: 10.1093/her/cyp046.

8. Delahoy, M.J., Whitaker, M., O'Halloran, A., Chai, S.J., Kirley P.D., Alden N. et. al. (2020). Characteristics and Maternal Birth Outcomes of Hospitalized Pregnant Women with Laboratory-Confirmed COVID-19 - COVID-NET, 13 States, March 1-August 22,2020. MMWR Morb Mortal Wkly Rep. ePub; DOI: http://dx.doi.org/10.15585/mmwr.mm6938e1.

9. Ellington, S., Strid, P., Tong, V.T., Woodworth, K., Galang, R.R., Zambrano, L. D., et al. (2020). Characteristics of Women of Reproductive Age with Laboratory-Confirmed SARS-CoV-2 Infection by Pregnancy Status - United States, January 22-June 7, 2020. MMWR Morb Mortal Wkly Rep; 69:769-775. DOI: http://dx.doi.org/10.15585/mmwr.mm6925a1.

10. Kirst, M., Shankardass, K., Bomze, S., Lofters, A. \& Quinonez, C. (2013). Sociodemographic data collection for health equity measurement: a mixed methods study examining public opinions. Int J Equity Health.;12:75. doi:10.1186/1475-9276-12-75. https://www.ncbi.nlm.nih.gov/pmc/articles/PMC3766029/

11. Panagiotakopoulos, L., Myers, T.R., Gee, J., Lipkind, H.S., Kharbanda, E. O., Ryan, D.S., et. al. (2020). SARS-CoV-2 Infection Among Hospitalized Pregnant Women: Reasons for Admission and Pregnancy Characteristics - Eight U.S. Health Care Centers, March 1May 30, 2020. MMWR Morb Mortal Wkly Rep. ePub; DOI: http://dx.doi.org/10.15585/mmwr.mm6938e2.

12. Petkovic, J., Duench, S.L., Welch, V., Rader, T., Jennings, A., Forster, A.J., \& Tugwell, P. (2019). Potential harms associated with routine collection of patient sociodemographic information: A rapid review. Health Expect:22:114-129. https://doi.org/10.1111/hex.12837

13. Stokes, E.K., Zambrano, L.D., Anderson, K.N., Marder, E.P., Raz, K.M., Burai Felix, S.E., et al. (2020). Coronavirus Disease 2019 Case Surveillance - United States, January 22-May 30, 2020. MMWR Morb Mortal Wkly Rep; 69:759-765. DOI:

Page 5/9 
http://dx.doi.org/10.15585/mmwr.mm6924e2.

14. Woodworth, K.R., Olsen, E.O., Neelam, V., Lewis, E.L., Galang, R.R., Oduyebo, T., et. al. (2020). Birth and Infant Outcomes Following Laboratory-Confirmed SARS-CoV-2 Infection in Pregnancy - SET-NET, 16 Jurisdictions, March 29-October 14, 2020. MMWR Morb Mortal Weekly Report, 69(44): 1635-1640.

15. Zambrano, L.D., Ellington, S., Strid P., Galang R.R., Oduyebo T., Tong, V.T., et al. (2020). Characteristics of Symptomatic Women of Reproductive Age with Laboratory-Confirmed SARS-CoV-2 Infection by Pregnancy Status -United States, January 22-October 3, 2020. MMWR Morb Mortal Weekly Report, 69(44): 1641-1647.

\section{Tables}


Table 1. Women of reproductive age with laboratory-confirmed COVID-19 that linked to birth or fetal death certificates for completed deliveries through December 31,2020 , by pregnancy status

\begin{tabular}{|c|c|c|c|c|c|c|c|c|}
\hline & \multicolumn{4}{|l|}{ Illinois } & \multicolumn{4}{|l|}{ Tennessee } \\
\hline & $\begin{array}{l}\text { Pregnancy } \\
=\text { 'Yes' }\end{array}$ & $\begin{array}{l}\text { Pregnancy } \\
=\text { 'No' or } \\
\text { missing }\end{array}$ & $\begin{array}{l}\text { Total } \\
\text { COVID+ }\end{array}$ & $\begin{array}{l}\% \text { correct } \\
\text { pregnancy } \\
\text { status }\end{array}$ & $\begin{array}{l}\text { Pregnancy } \\
=\text { 'Yes' }\end{array}$ & $\begin{array}{l}\text { Pregnancy = } \\
\text { 'No' or } \\
\text { missing }\end{array}$ & $\begin{array}{l}\text { Total } \\
\text { COVID+ }\end{array}$ & $\begin{array}{l}\% \text { correct } \\
\text { pregnancy } \\
\text { status }\end{array}$ \\
\hline Total & 1936 & 2340 & 4,276 & $45.3 \%$ & 872 & 1,198 & 2,070 & $42.1 \%$ \\
\hline
\end{tabular}

\section{Race/ethnicity †}

\begin{tabular}{|c|c|c|c|c|c|c|c|c|}
\hline $\begin{array}{l}\text { White, non- } \\
\text { Hispanic }\end{array}$ & $\begin{array}{l}525 \\
(27.1 \%)\end{array}$ & $\begin{array}{l}750 \\
(32.1 \%)\end{array}$ & 1,275 & $41.2 \%$ & $\begin{array}{l}405 \\
(46.4 \%)\end{array}$ & $511(42.7 \%)$ & 916 & $44.2 \%$ \\
\hline $\begin{array}{l}\text { Black, non- } \\
\text { Hispanic }\end{array}$ & $\begin{array}{l}413 \\
(21.3 \%)\end{array}$ & $\begin{array}{l}431 \\
(18.4 \%)\end{array}$ & 844 & $48.9 \%$ & $\begin{array}{l}166 \\
(19.0 \%)\end{array}$ & $312(26.0 \%)$ & 478 & $34.7 \%$ \\
\hline $\begin{array}{l}\text { Hispanic or } \\
\text { Latino }\end{array}$ & $\begin{array}{l}868 \\
(44.8 \%)\end{array}$ & $\begin{array}{l}988 \\
(42.2 \%)\end{array}$ & 1,856 & $46.8 \%$ & $\begin{array}{l}259 \\
(29.7 \%)\end{array}$ & 319 (26.6\%) & 578 & $44.8 \%$ \\
\hline $\begin{array}{l}\text { Other race, non- } \\
\text { Hispanic*}\end{array}$ & $\begin{array}{l}104 \\
(5.4 \%)\end{array}$ & $\begin{array}{l}134 \\
(5.7 \%)\end{array}$ & 238 & $43.7 \%$ & $41(4.7 \%)$ & $53(4.4 \%)$ & 94 & $43.6 \%$ \\
\hline $\begin{array}{l}\text { Missing, refused } \\
\text { or unknown race }\end{array}$ & $26(1.3 \%)$ & 37 (1.6\%) & 63 & $41.3 \%$ & $1(0.1 \%)$ & $3(0.3 \%)$ & 4 & $25.0 \%$ \\
\hline
\end{tabular}

\section{Maternal age}

(yrs)

\begin{tabular}{|c|c|c|c|c|c|c|c|c|}
\hline $15-24$ & $\begin{array}{l}507 \\
(26.2 \%)\end{array}$ & $\begin{array}{l}602 \\
(25.7 \%)\end{array}$ & 1,109 & $45.7 \%$ & $\begin{array}{l}250 \\
(28.7 \%)\end{array}$ & 389 (32.5\%) & 639 & $39.1 \%$ \\
\hline $25-34$ & $\begin{array}{l}1,077 \\
(55.6 \%)\end{array}$ & $\begin{array}{l}1,325 \\
(56.6 \%)\end{array}$ & 2,402 & $44.8 \%$ & $\begin{array}{l}493 \\
(56.5 \%)\end{array}$ & 648 (54.1\%) & 1,141 & $43.2 \%$ \\
\hline $35-44$ & $\begin{array}{l}352 \\
(18.2 \%)\end{array}$ & $\begin{array}{l}413 \\
(17.6 \%)\end{array}$ & 765 & $46.0 \%$ & $\begin{array}{l}129 \\
(14.8 \%)\end{array}$ & $161(13.4 \%)$ & 290 & $44.5 \%$ \\
\hline
\end{tabular}

\section{Maternal}

education $†$

\begin{tabular}{lllllllll}
$\begin{array}{l}\text { Less than high } \\
\text { school }\end{array}$ & $\begin{array}{l}293 \\
(15.1 \%)\end{array}$ & $\begin{array}{l}304 \\
(13.0 \%)\end{array}$ & 597 & $\mathbf{4 9 . 1 \%}$ & $\begin{array}{l}191 \\
(21.9 \%)\end{array}$ & $250(20.9 \%)$ & 441 & $\mathbf{4 3 . 3 \%}$ \\
\hline $\begin{array}{l}\text { High school } \\
\text { diploma/GED }\end{array}$ & $\begin{array}{l}633 \\
(32.7 \%)\end{array}$ & $\begin{array}{l}712 \\
(30.4 \%)\end{array}$ & 1,345 & $\mathbf{4 7 . 1 \%}$ & $\begin{array}{l}216 \\
(24.8 \%)\end{array}$ & $341(28.5 \%)$ & 557 & $\mathbf{3 8 . 8 \%}$ \\
\hline $\begin{array}{l}\text { Associate's/some } \\
\text { college }\end{array}$ & $\begin{array}{l}559 \\
(28.9 \%)\end{array}$ & $\begin{array}{l}673 \\
(28.8 \%)\end{array}$ & 1,232 & $\mathbf{4 5 . 4 \%}$ & $\begin{array}{l}275 \\
(31.5 \%)\end{array}$ & $323(27.0 \%)$ & 598 & $\mathbf{4 6 . 0 \%}$ \\
$\begin{array}{l}\text { Bachelor's degree } \\
\text { or higher }\end{array}$ & $\begin{array}{l}408 \\
(21.1 \%)\end{array}$ & $\begin{array}{l}588 \\
(25.1 \%)\end{array}$ & 996 & $\mathbf{4 1 . 0 \%}$ & $\begin{array}{l}186 \\
(21.3 \%)\end{array}$ & $276(23.0 \%)$ & 462 & $\mathbf{4 0 . 2 \%}$ \\
$\begin{array}{l}\text { Missing or } \\
\text { unknown } \\
\text { education }\end{array}$ & $43(2.2 \%)$ & $63(2.7 \%)$ & 106 & $\mathbf{4 0 . 6 \%}$ & $4(0.5 \%)$ & $8(0.7 \%)$ & 12 & $\mathbf{3 3 . 3 \%}$ \\
\hline & & & & & & &
\end{tabular}

Maternal insurance (delivery

payer source) †

\begin{tabular}{|lllllllll|} 
Public & $\begin{array}{l}1,141 \\
(58.9 \%)\end{array}$ & $\begin{array}{l}1,239 \\
(52.9 \%)\end{array}$ & 2,380 & $47.9 \%$ & $\begin{array}{l}453 \\
(52.0 \%)\end{array}$ & $670(55.9 \%)$ & 1,123 & $40.3 \%$ \\
\hline Private & 760 & $\begin{array}{l}1,012 \\
(39.3 \%)\end{array}$ & 1,772 & $\mathbf{4 2 . 9 \%}$ & $\begin{array}{l}388 \\
(44.5 \%)\end{array}$ & $459(38.3 \%)$ & 847 & $\mathbf{4 5 . 8 \%}$ \\
\hline Other/none** & $27(1.4 \%)$ & $70(3 \%)$ & 97 & $27.8 \%$ & $27(3.1 \%)$ & $54(4.5 \%)$ & 81 & $33.3 \%$
\end{tabular}




\begin{tabular}{|c|c|c|c|c|c|c|c|c|}
\hline Missing & $8(0.4 \%)$ & $19(0.8 \%)$ & 27 & $29.6 \%$ & $4(0.5 \%)$ & $15(1.3 \%)$ & 19 & $21.1 \%$ \\
\hline \multicolumn{9}{|c|}{$\begin{array}{l}\text { 1st Trimester prenatal care } \\
\text { entry } ¥\end{array}$} \\
\hline Yes & $\begin{array}{l}1,442 \\
(74.5 \%)\end{array}$ & $\begin{array}{l}1,677 \\
(71.7 \%)\end{array}$ & 3,119 & $46.2 \%$ & $\begin{array}{l}664 \\
(76.2 \%)\end{array}$ & $833(69.5 \%)$ & 1,497 & $44.4 \%$ \\
\hline No & $\begin{array}{l}398 \\
(20.6 \%)\end{array}$ & $\begin{array}{l}555 \\
(23.7 \%)\end{array}$ & 953 & $41.8 \%$ & $\begin{array}{l}188 \\
(21.6 \%)\end{array}$ & 341 (28.5\%) & 529 & $35.5 \%$ \\
\hline $\begin{array}{l}\text { Missing or } \\
\text { unknown }\end{array}$ & $96(5.0 \%)$ & $\begin{array}{l}108 \\
(4.6 \%)\end{array}$ & 204 & $47.1 \%$ & $20(2.3 \%)$ & $24(2.0 \%)$ & 44 & $45.5 \%$ \\
\hline
\end{tabular}

\section{Month of specimen collection \\ †}

\begin{tabular}{|c|c|c|c|c|c|c|c|c|}
\hline March 2020 & $55(2.8 \%)$ & $25(1.1 \%)$ & 80 & $68.8 \%$ & $15(1.7 \%)$ & $7(0.6 \%)$ & 22 & $68.2 \%$ \\
\hline April 2020 & $\begin{array}{l}329 \\
(17.0 \%)\end{array}$ & $\begin{array}{l}280 \\
(12.0 \%)\end{array}$ & 609 & $54.0 \%$ & 57 (6.5\%) & $30(2.5 \%)$ & 87 & $65.5 \%$ \\
\hline May 2020 & $\begin{array}{l}412 \\
(21.3 \%)\end{array}$ & $\begin{array}{l}316 \\
(13.5 \%)\end{array}$ & 728 & $56.6 \%$ & $\begin{array}{l}91 \\
(10.4 \%)\end{array}$ & $48(4.0 \%)$ & 139 & $65.5 \%$ \\
\hline June 2020 & 169 (8.7\%) & $\begin{array}{l}117 \\
(5.0 \%)\end{array}$ & 286 & $59.1 \%$ & $\begin{array}{l}157 \\
(18.0 \%)\end{array}$ & $153(12.8 \%)$ & 310 & $50.1 \%$ \\
\hline July 2020 & 172 (8.9\%) & $\begin{array}{l}172 \\
(7.4 \%)\end{array}$ & 344 & $50.0 \%$ & $\begin{array}{l}202 \\
(23.2 \%)\end{array}$ & $250(20.9 \%)$ & 452 & $44.5 \%$ \\
\hline August 2020 & $143(7.4 \%)$ & $\begin{array}{l}221 \\
(9.4 \%)\end{array}$ & 364 & $39.3 \%$ & $\begin{array}{l}125 \\
(14.3 \%)\end{array}$ & $146(12.2 \%)$ & 271 & $46.1 \%$ \\
\hline September 2020 & $88(4.5 \%)$ & $\begin{array}{l}185 \\
(7.9 \%)\end{array}$ & 273 & $32.2 \%$ & $62(7.1 \%)$ & $90(7.5 \%)$ & 152 & $41.1 \%$ \\
\hline October 2020 & $\begin{array}{l}235 \\
(12.1 \%)\end{array}$ & $\begin{array}{l}232 \\
(9.9 \%)\end{array}$ & 467 & $50.3 \%$ & $\begin{array}{l}89 \\
(10.2 \%)\end{array}$ & $117(9.8 \%)$ & 206 & $42.9 \%$ \\
\hline November 2020 & 180 (9.3\%) & $\begin{array}{l}582 \\
(24.9 \%)\end{array}$ & 762 & $23.6 \%$ & $52(6.0 \%)$ & $183(15.3 \%)$ & 235 & $21.7 \%$ \\
\hline December 2020 & 153 (7.9\%) & $\begin{array}{l}210 \\
(9.0 \%)\end{array}$ & 363 & $42.1 \%$ & $22(2.5 \%)$ & $174(14.5 \%)$ & 196 & $10.3 \%$ \\
\hline
\end{tabular}

\section{Pregnancy trimester of specimen collection}

$\dagger$

\begin{tabular}{|c|c|c|c|c|c|c|c|c|}
\hline First trimester & $129(6.7 \%)$ & $\begin{array}{l}162 \\
(6.9 \%)\end{array}$ & 291 & $44.3 \%$ & $60(6.9 \%)$ & $42(3.5 \%)$ & 102 & $58.8 \%$ \\
\hline Second trimester & $\begin{array}{l}451 \\
(23.3 \%)\end{array}$ & $\begin{array}{l}504 \\
(21.5 \%)\end{array}$ & 955 & $47.2 \%$ & $\begin{array}{l}324 \\
(37.2 \%)\end{array}$ & 245 (20.5\%) & 569 & $56.9 \%$ \\
\hline Third trimester & $\begin{array}{l}792 \\
(40.9 \%)\end{array}$ & $\begin{array}{l}1,066 \\
(45.6 \%)\end{array}$ & 1,858 & $42.6 \%$ & $\begin{array}{l}436 \\
(50.0 \%)\end{array}$ & $576(48.1 \%)$ & 1,012 & $43.1 \%$ \\
\hline Delivery & $\begin{array}{l}564 \\
(29.1 \%)\end{array}$ & $\begin{array}{l}608 \\
(26.0 \%)\end{array}$ & 1,172 & $48.1 \%$ & $52(6.0 \%)$ & 335 (28.0\%) & 387 & $13.4 \%$ \\
\hline
\end{tabular}

* Other race includes Asian or American Indian or Alaska Native or Native Hawaiian or Other Pacific Islander or multiple races (not presented separately because of small cell sizes).

** Includes self-pay.

† chi-square test $p$-value $<0.05$ for Illinois 
$\ddagger$ chi-square test $p$-value $<0.05$ for Tennessee

Page $9 / 9$ 